\title{
Research on the Incentive Mechanism of Academic Subject Competition
}

\author{
Yang Weizhi, Zhang Liucheng, Yin Long, Cao Guibing \\ Harbin University of Commerce, Harbin, 150028, China
}

Keywords: subject competition; incentive subject; incentive object; incentive mechanism

\begin{abstract}
A sound incentive mechanism is the driving force for academic competition in universities. In order to fully mobilize students, instructors to participate in, organize the enthusiasm of the discipline competition, stimulate their potential, and achieve good results, we must build a reasonable incentive mechanism. Aiming at the phenomenon that the instructors and participating students in the existing discipline competitions in colleges and universities are not engaged enough and are not active, the paper discusses the complete operation framework of the interaction between the motivation subject and the incentive object in the subject competition. I hope that I can enlighten the improvement and improvement of the incentive mechanism of the discipline competition in various universities.
\end{abstract}

\section{Introduction}

The long-term training model of colleges and universities has made the social practice ability of college students seriously out of touch with social needs. The subject competition is a mass scientific and technological activity for college students. It is an activity that examines students' basic theoretical knowledge and practical problem solving ability in a competitive way based on the combination of classroom teaching and classroom teaching. Therefore, as a extension of the theoretical knowledge of the classroom, the subject competition has become the focus of practical teaching. However, the subject competition of many colleges and universities is more formal than the content in the course of operation. Many college students and teachers are not very involved. There are many reasons for this. Many studies have shown that scientific and rational academic competition incentives are the key factors to improve the effectiveness of academic competition. Effective incentive mechanism plays an irreplaceable role in stimulating the enthusiasm of college teachers and students and mobilizing the subjective initiative of teachers and students. Without the right incentives, it is difficult for schools to achieve excellent competition results. Most of the existing researches are discussed from the perspective of incentive content and incentives, but this is only a part of the incentive mechanism, which is incomplete and one-sided.

\section{Design of the Incentive Mechanism of Disciplinary Professional Competition}

The incentive mechanism is the sum of the structure, mode, relationship and evolution law of the system of the incentive system that uses the various incentives to make and normalize and relatively immobilize, and to interact with and restrict each other. Under the enlightenment of the incentive mechanism construction model designed by Liu Zhengzhou, the author constructed a model of the incentive mechanism for the disciplines in colleges and universities, as shown in the following figure.

\subsection{Motivating two-way communication between the subject and the object}

The main body of the subject competition incentives is the school (including relevant functional departments) and the secondary colleges. The inspiring objects are the instructors and participating students. Among them, the school is the highest decision-maker of the discipline competition, and is also the top-level designer of the relevant system of the discipline competition, including the incentive mechanism; the secondary college is the implementer of the school policy, the maker of the implementation rules and the provider of the competition venue facilities. Important role; the 
instructor is the leader and payer of the subject competition, responsible for finding the competition venue, purchasing instruments and consumables, selecting the students, directly guiding the students in the daily training and the whole process of the competition, their ability level and participation enthusiasm for the discipline The effectiveness of the competition has a decisive influence; the participating students are the main body and gains of the subject competition, and their knowledge and skills and the enthusiasm of participating in the competition have a direct and important impact on the effectiveness of the competition. In an effective incentive mechanism, the subject and object of the incentive must have a two-way communication process. This exchange enables schools and secondary schools to understand the motivations of students and teachers, their values and some of their demands. At the same time, the school also clarifies the goals of the school to the instructors and participating students, the value orientation advocated by the school, the reward method for winning the competition and the clear evaluation criteria. In the two-way communication between the incentive subject and the object, the incentive subject holds the resources of the incentive and should be in a dominant position in the communication. However, at present, some colleges and universities generally have insufficient communication and communication between the parties involved in the competition: teachers and students do not understand the intentions of the school or some information about the competition. Some systems or measures introduced by the school cannot mobilize the participation of teachers and students. Enthusiasm. Adequate communication can make the school's relevant academic competition system closer to the actual needs of the instructors and participating students, and help to establish a correct view of participation, preventing some students from playing for the competition just for the sake of the game, but neglecting the subject. The competition itself has a long-term function.

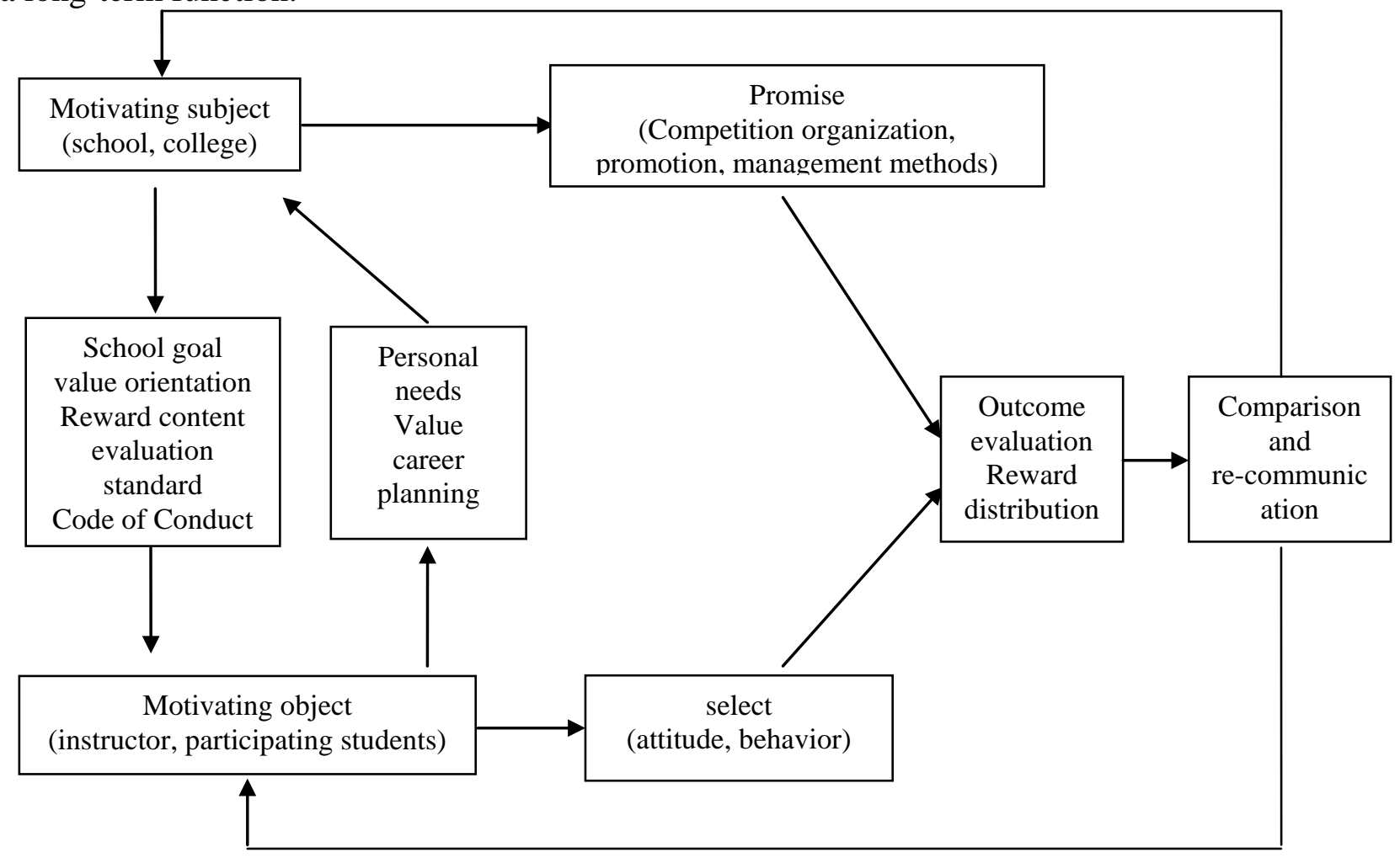

Fig.1

\subsection{The commitment of the motivating subject and the choice of the motivating object}

Through the two-way communication in the previous step, the relevant departments of the school and the secondary colleges need to organize the competition accordingly, including the clear competition management organization, the basis for evaluating the competition level, the corresponding specific incentive measures and the competition in the school. The propaganda, etc., is the institutionalized commitment of the incentive body to the incentive object, and also reflects the 
degree of emphasis on the competition. When the incentive object receives the promise of the incentive subject, it will make corresponding choices, participate in the competition or not participate in the competition, pay attention to the competition or not pay attention to the competition, and invest in the competition is hard work or not. Studies have shown that the more clear and specific the incentive body's commitment to motivating the object, the more it can guide the motivating object to make a positive choice.

\subsection{Evaluation of competition results and distribution of rewards}

This is a very critical part of the incentive mechanism. Its pros and cons directly affect the time and energy input of teachers and students in the subject competition and the final competition results. At present, the evaluation of the results of the competitions and the distribution of rewards are more and more comprehensive.

First of all, from the perspective of the evaluation of the results of the competition, many colleges and universities have basically adopted the method of classification evaluation for the subject competition. The highest level is a competition sponsored by the National Education Administration, generally referred to as a type of competition or a category A competition. Secondly, competitions sponsored by provincial education administrations or sponsored by national-level societies are generally referred to as second-class competitions or B-class competitions. Finally, competitions sponsored by some enterprises or local associations are generally referred to as three types of competitions or C. Class competition. In principle, these divisions are basically feasible. However, there are fewer competitions sponsored by the national education administration, and one round of competitions has taken place, and the number of students participating is very small. In recent years, some academic competitions sponsored by national societies, research institutes and enterprises have sprung up. The gold content is no less than that sponsored by the national or provincial education administration. However, because it is not officially hosted, many colleges and universities do not Recognize its legitimacy. This one-size-fits-all approach has greatly hurt the enthusiasm and enthusiasm of some instructors and participating students. In fact, the solution is very simple. Schools and professional instructors provide clear evaluation indicators, such as the number of participating schools and students, the number of years of competition, the social influence, the difficulty of winning the competition, and the normative nature of the competition. The results of the competition are fair and transparent. Rather than being simple and rude, the organizer is the only evaluation indicator.

Secondly, from the perspective of the reward and distribution of the competition results, most colleges mainly use material rewards and spiritual rewards. For the instructors, it is mainly to appraise the top points, the title evaluation and the year-end assessment points, public recognition, give a certain amount of work, and issue a certain amount of bonuses. For the participating students, it is mainly for the academic year to add points, the party members to join the party plus points, identified as elective credits, insurance research points and a certain amount of bonuses. Compared with previous years, the rewards and distributions for instructors and participating students are relatively comprehensive, but the intensity of incentives is not enough compared with the efforts of instructors and participating students. Subject professional competitions generally last a long time, and students use the spare time to complete, students may pay a lot of energy, and in the end may not have a good competition results. The competition results are closely related to the final rewards. In particular, the rewards of most competitions are linked to the competition levels specified above. The lower the number of higher-level discipline competitions, the smaller the probability of winning. . The instructor and the participating students will not be willing to participate in the competition without any expectation of winning the prize. After all, the award rules for the relevant academic competitions in the school are award-oriented. Compared with the more rewarding Class A competitions, many of the awards in the B-class competitions are formal and symbolic. After the students have paid a lot of time and energy, the rewards of some competitions are not enough to offset the expenses related to the students' participation (such as entry fee, material fee, printing fee, etc.). The investigation of the subject group's professional competitions also supported this conclusion. 
Sixty percent of the students think that the lack of funds or the lack of special funding support is the biggest difficulty encountered during the competition. The instructor has already undertaken heavy teaching and scientific research tasks. Instructing students to participate in the competition often takes up a lot of energy and time for the instructors, and the corresponding rewards are too few. After guiding a subject competition, many instructors will retreat. The research team's survey shows that nearly $60 \%$ of students can't find a teacher.

To solve this problem, we can reclassify the competition level and expand the incentive surface; for some colleges with relatively tight budgets, we can increase the intensity of other incentives. For example, to improve the instructor's appraisal and extra points, give a certain amount of work to the instructors who receive the stage awards. For students, they will increase the bonus points of the insurance research, and the students who receive the stage awards will be given corresponding rewards and recognitions.

\subsection{Comparison and re-engagement of stimulating objects}

Adams's theory of fairness tells us that not only the absolute value of reward, but also the relative value of reward, affecting the incentive effect. Instructors and participating students often compare their rewards with those of other colleges and compare them with their own past to see if they are satisfied with the rewards they receive from this activity. The research team's survey found that in the process of discussion and communication of some competitions, the incentives for teachers and students to participate in the school and college level are topics of common concern. In some colleges and universities that have no incentives, the enthusiasm of the instructors and participating students is obviously not high. At the school level, attention should be paid to the impact of such communication on the behavior and attitudes of instructors and participating students.

\section{Conclusion}

Disciplinary competition is a systematic project that requires the joint efforts of the subject and the object. At the school level, the corresponding incentive mechanism for the competition plays an important guiding role in guiding the enthusiasm and initiative of the teachers and participating students to participate in the competition. The pros and cons of the relevant incentives also affect the time, energy input and final competition results of the students in the design competition. It is true that in guiding students to participate in design competitions, there should be no single emphasis on high rewards for students to motivate students to actively participate in the competition. However, under the background of the current era of innovation and entrepreneurship, it is one of the important means to enhance the comprehensive influence and popularity of all kinds of colleges and universities, and to promote the academic competition incentive mechanism.

\section{Acknowledgements}

2017 Harbin University of Commerce Practical Teaching Reform and Research Project, "Study on the Cultivation of Practical Ability of Economics and Management Majors Driven by Discipline Competition"; Heilongjiang Province Educational Science Planning Subject"Comprehensive evaluation research on national experimental teaching demonstration center" (GBE1317011).

\section{References}

[1] Liu Zhengzhou. Management Incentives. Shanghai University of Finance and Economics Press [M]. 1999 edition.

[2] Wang Fenglian, Wang Banglun, "Study on the Incentive Mechanism of University Discipline Competition Based on the Cultivation of Innovative Practice Ability” [J], Journal of Chongqing University of Science and Technology 2017. (2)

[3] Lu Yan "Study on the Design, Organization and Supporting Management Mechanism of 
University Discipline Competition” [J], Journal of Hubei University of Economics 2016. (5)

[4] Zhang Yumeng, Lei Wenwu, “Analysis of the Level Improvement Model of College Students' Academic Competitions” [J], Journal of Ningbo University, 2011 (9)

[5] Wang Xuejiang, "Construction of the Management System of Subjects and Competitions in Financial and Economic Colleges” [J], Economics and Management 2016. (7) 